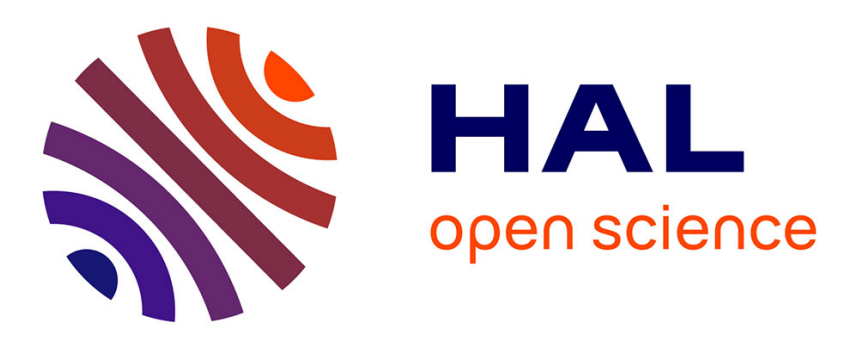

\title{
Characterization and modeling of sintering of polymer particles
}

\author{
Monir Asgarpour, Farid Bakir, Sofiane Khelladi, A. Khavandi, Abbas
}

Tcharkhtchi

\section{- To cite this version: \\ Monir Asgarpour, Farid Bakir, Sofiane Khelladi, A. Khavandi, Abbas Tcharkhtchi. Characterization and modeling of sintering of polymer particles. Journal of Applied Polymer Science, 2011, 119 (5), pp.2784-2792. 10.1002/app.32924 . hal-02413041}

\section{HAL Id: hal-02413041 \\ https://hal.science/hal-02413041}

Submitted on 16 Dec 2019

HAL is a multi-disciplinary open access archive for the deposit and dissemination of scientific research documents, whether they are published or not. The documents may come from teaching and research institutions in France or abroad, or from public or private research centers.
L'archive ouverte pluridisciplinaire HAL, est destinée au dépôt et à la diffusion de documents scientifiques de niveau recherche, publiés ou non, émanant des établissements d'enseignement et de recherche français ou étrangers, des laboratoires publics ou privés. 


\title{
Characterization and Modeling of Sintering of Polymer Particles
}

\author{
M. Asgarpour, ${ }^{1}$ F. Bakir, ${ }^{2}$ S. Khelladi, ${ }^{2}$ A. Khavandi, ${ }^{3}$ A. Tcharkhtchi ${ }^{1}$ \\ ${ }^{1}$ Le Laboratoire Procédés et Ingénierie en Mécanique et Matériaux, Arts et Métiers ParisTech, \\ 151 Bd de l'Hôpital, Paris, France \\ ${ }^{2}$ Laboratoire de Dynamique des Fluides, Arts et Métiers ParisTech, 151 Bd de l'Hôpital, Paris, France \\ ${ }^{3}$ Department of Material Engineering, Iran University of Science and Technology, Tehran, Iran
}

\begin{abstract}
An experimental study of simultaneous sintering of several particles has been carried out using spherical polymer grains. Considering rotational molding condition, coalescence of several grains in contact, happens simultaneously on internal surface of the mould. Theoretical model based on the effect of surface tension and viscosity can accurately predict the coalescence of a pairs of grains. However, it was observed in this study that coalescence rate changes with presence of neighboring grains and their position and the theoretical model pro-
\end{abstract}

\section{INTRODUCTION}

Rotational molding is a relative inexpensive method used originally for fabricating the hollow parts like toys, storage drums, and other products. The major difficult faced, during its application for manufacturing of complicated industrial parts, is to control object thickness, surface quality, and presence of air bubbles in the material. The work done by research community, during past many years has improved the process capacity and still a lot of work is being done to understand material behavior during actual molding process.

In rotational molding, polymer is introduced in powder form into a mold, which rotates biaxially. This powder is then heated and once it reaches the melting point, the grains start to melt and to stick to the mold surface and to each other. The phenomenon of adhesion of grains during melting and interdiffusion of them is called coalescence. Because of this inter-diffusion, the inter space distance between the grains reduces and the coalescence will be followed with another physical phenomenon which is called densification. "Sintering" is the term accepted in the material science literature for the combined action of coalescence and densification.

Correspondence to: M. Asgarpour (m_asgary2002@yahoo. com). posed for two grains, is not able to predict the coalescence rate of mutli-grains. Based on this finding, we have modified this model with taking into account the effect of neighboring particles in the sintering rate of multi-grains. Obtained modified model is capable of predicting the multi-grains sintering rate observed in this study.

Key words: sintering; modeling; plastics; rotational molding; surface tension

Polymer is used in powder form in many industries like rotational molding, so sintering is inherent to this process. Rotational molding is a free stress and free pressure method, so sintering is a fundamental and controlling phenomenon. ${ }^{1-3}$ The cycle time of processing depends on sintering. Also final properties of molded parts depend directly in the sintering process. Air bubble appearance and weak mechanical properties of final part are the consequence of unsuitable sintering of powder particles. ${ }^{4}$

Better understanding of sintering process is highly important for process control of industries which use polymer in powder form. Once two grains in contact reach the melting point, an interface is formed between them. This interface spreads with time and finally these two grains combine to form a single mass of polymer (Fig. 1).

Different studies have investigated the effect of parameters, such as temperature, viscosity, grain size, etc., on the coalescence process. The first analytical model for coalescence of two spherical grains is proposed by Frenkel. ${ }^{1}$ According to him, coalescence of two particles occurs by viscous flow. In his model, Frenkel suggested that the deformation rate is constant during coalescence of two grains. Comparison with the experimental results shows that the Frenkel's model is only valid for the first stages of Newtonian flows. ${ }^{5-7}$ After Frenkel, different researchers ${ }^{8-10}$ modified his model to adapt it to the complete coalescence phenomena of Newtonian and viscous-Newtonian flows. There are also several 


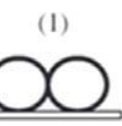

S 3
(2)

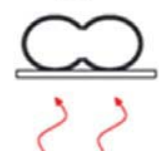

(3)

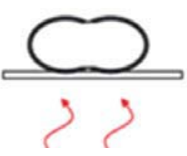

(4)

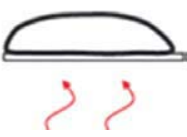

Figure 1 Schematic of the coalescence of two grains (1) Initiation, (2) and (3) Neck's growth, (4) end of coalescence. [Color figure can be viewed in the online issue, which is available at wileyonlinelibrary.com.]

numerical simulations presented by different authors for viscous flow sintering. ${ }^{11-14}$ Majority of these works are about the sintering of ceramics and metals. $2,15,16$

As the several works have been done in the sintering of ceramics and metals, this process is identified and modeled for these materials. During sintering of ceramics and metals (materials with high melting temperature) solid-sate sintering occurs due to diffusion at high temperature. For these materials that have very high melting points, sintering occurs at temperatures lower than their melting points. ${ }^{17}$ During sintering of alloys, the grains growth occurs due to a decrease in the interfacial surface energy. This grains growth is a combined result of liquid diffusion, solid diffusion, and vapor diffusion. In these materials, there is simultaneous solid-state sintering coupled with the diffusion through the liquid phase. Solid volume fraction, multiple diffusion mechanisms, and presence of a solid skeleton affect the rate of grain coarsening. ${ }^{18}$

The Newtonian flow models that are valid for ceramics and metals may not accurately represent polymer sintering. ${ }^{8,19,20}$ The sintering of polymers occurs often at temperatures higher than their melting point (without pressure, semi-crystalline) or their glass transition temperature (under pressure, amorphous). To model polymer sintering, the role of diffusion was studied, but later it was shown that the activation energy for diffusion of organic material is very high and as a result diffusion cannot have an important role in the sintering of polymers. ${ }^{21}$ The effect of viscoelasticity on coalescence behavior was also studied but the proposed models were not in good agreement with experimental results. ${ }^{3,19,20}$

Bellehumeur et al. ${ }^{22}$ proposed a model for coalescence of two spherical grains of polymer. Their model is based on the Frenkel's model but it takes into account the change in grains sizes and grains surfaces during coalescence. They used convicted Maxwell constitutive equation to introduce viscoelastic behavior and calculated the viscous dissipation of polymer to balance it with the work of surface tension. They validated their model with experimental results using different polymers. Recently, their work was also validated by Perot et $\mathrm{al}^{23}$

Interfacial phenomena and reactions are important in several processes. These properties (such as surface tension and interfacial surface energy) are controlling parameters of various phenomena such as wetting and adhesion of liquid on solid surfaces. Surface properties of polymers affect the final properties of the composites, as well as multiphase polymer systems. ${ }^{24-26}$ It was shown that, surface tension is the driving force of polymers sintering. Coalescence of two similar grains (melted polymer grains) occurs to reduce their total free surface. Smaller surface means lower energy and higher stability. So measuring of the surface properties of polymers (in liquid and solid state) has a great importance in polymer industries. In general there is a variety of experimental techniques for determination of surface tension.

Almost all of the polymers sintering studies have considered the sintering of two grains. But in reality, during rotational molding (and also other processing methods), more than two grains are in contact and they fuse together simultaneously. To our best knowledge, there is no investigation done on the
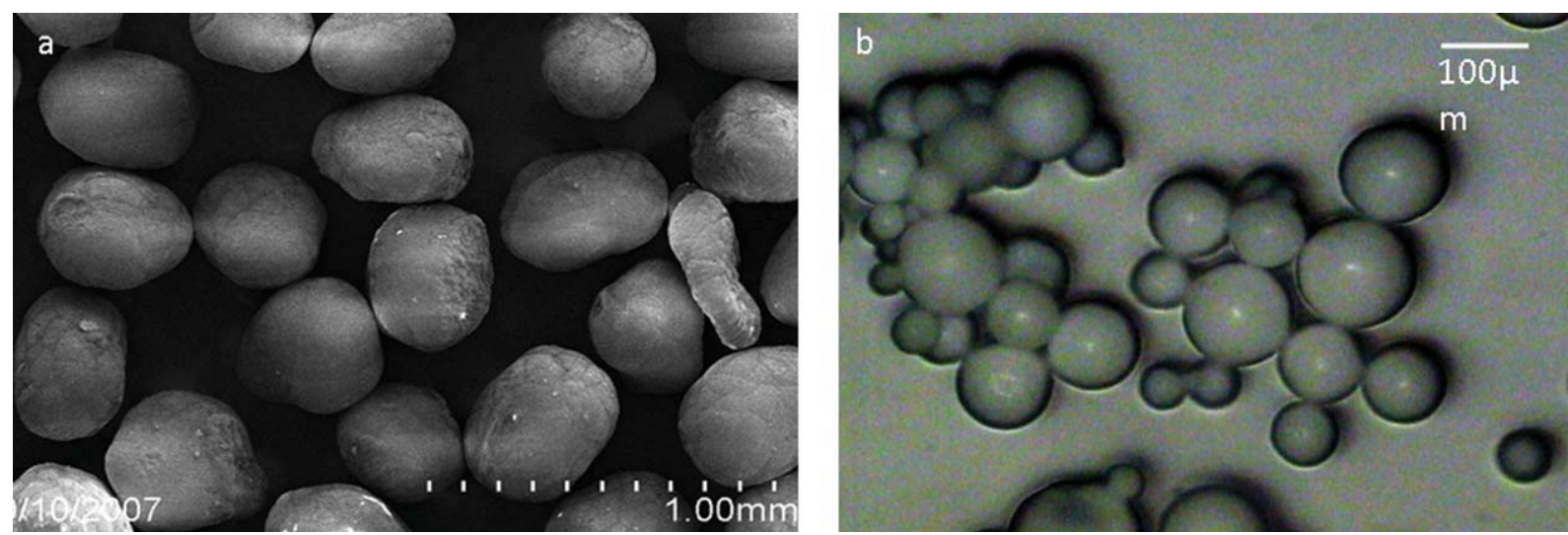

Figure 2 Powder particles of (a) PP and (b) PVDF. [Color figure can be viewed in the online issue, which is available at wileyonlinelibrary.com.] 
TABLE I

Material Properties

\begin{tabular}{|c|c|c|c|c|c|c|}
\hline Polymer & $\begin{array}{l}\text { Chemical } \\
\text { structure }\end{array}$ & $\begin{array}{l}T_{m} \\
\left({ }^{\circ} \mathrm{C}\right)\end{array}$ & $\begin{array}{c}\text { Zero-shear } \\
\text { viscosity (Pa s) }\end{array}$ & $\begin{array}{l}\text { Surface tension } \\
\qquad(\mathrm{mN} / \mathrm{m})\end{array}$ & $\begin{array}{c}\text { Sizes of } \\
\text { grains }(\mu \mathrm{m})\end{array}$ & $\begin{array}{l}\text { Shape of } \\
\text { grains }\end{array}$ \\
\hline PVDF & $-\left[\mathrm{CH}_{2} \mathrm{CF}_{2}\right] n-$ & 176 & $2486\left(\right.$ at $\left.220^{\circ} \mathrm{C}\right)$ & 34.1 (at $218.6^{\circ} \mathrm{C}$ ) & $20-100$ & Spherical \\
\hline PP & $-\left[\mathrm{CH}_{2} \mathrm{CHCH}_{3}\right]-$ & 167 & 3608 (at $190^{\circ} \mathrm{C}$ ) & 22.4 (at $191.7^{\circ} \mathrm{C}$ ) & $100-600$ & Spherical \\
\hline
\end{tabular}

coalescence of polymer multi-grains and the effect of neighboring grains in the sintering rate.

In this article, we studied the coalescence of multigrains. We modified Bellehumeur's proposed model by adding a geometrical factor which takes into account the effect of neighboring grains and their positions on the coalescence rate. This modified model is validated by experimental results obtained by using two different polymers.

\section{MATERIALS AND METHODS}

Two different polymers were used during this work: Poly propylene (PP), supplied by ICOPOLYMERS and polyvinylidene fluoride (PVDF), supplied by Solvay company of Belgium. Both of them were used in powder comprising spherical particles (Fig. 2). The sizes of PP and PVDF grains range from 100 to $600 \mu \mathrm{m}$ and 20 to $100 \mu \mathrm{m}$, respectively. Dynamic viscosities of these polymers were measured by an ARES rheometer (from TA Instruments Company) using parallel plates with a gap of $1 \mathrm{~mm}$ under nitrogen to avoid degradation. Thermal properties were determined by Differential Scanning Calorimetry (DSC) Q10 with TA instrument ${ }^{\circledR}$.

The particles of the same grain size were separated, using a set of sieves with different opening size, to investigate the coalescence of unique size particles. Surface tensions of these polymers were measured at different temperatures by using a drop shape analysis system DSA100 from KRÜSS ${ }^{\odot}$. Table I presents the different properties of the used polymers.

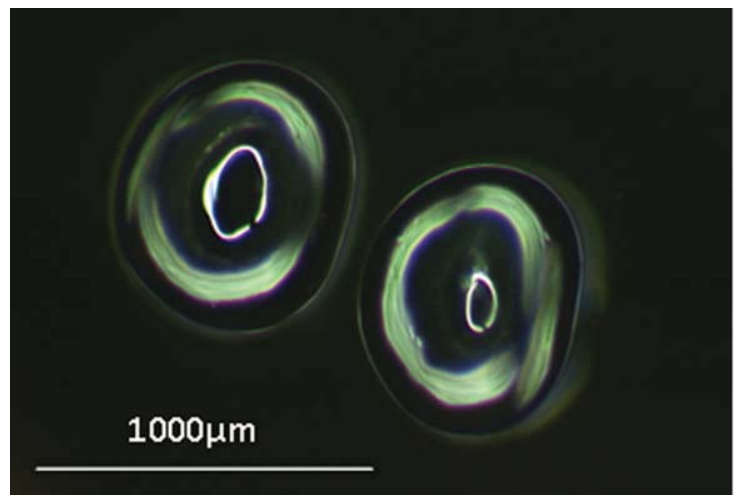

Sintering experiments were performed using a heat chamber fabricated by Mettler Company controlled with a central processor. A digital camera (JAI) attached to an optical microscope (Olympus) was used to record the sintering phenomena at a rate of one photo per second. Using unique size particles, different samples having different number of grains at different positions were prepared. After introducing these samples into the heat chamber, heating phase was started.

The heating of the grains was performed in two stages. During the first stage, the grains were heated up to until $5^{\circ} \mathrm{C}$ below their melting point at a heating rate of $10^{\circ} \mathrm{C} / \mathrm{min}$. To obtain an isothermal condition and to avoid temperature gradient in the grains, in the second stage, heating was done at a slower rate of $1^{\circ} \mathrm{C} / \mathrm{min}$ till reaching sintering temperature. Once reaching sintering temperature, isotherm condition was maintained by a central processor. The neck formed between the particles was measured at different times intervals using Ellix ${ }^{\odot}$ image analysis software. Sintering rate is calculated as the ratio of the half of neck size and the grain radius at defined time intervals. The coalescence of two grains is considered to be complete when this ratio is equal to 1 .

To validate the experimental procedure, the same experimental was repeated by heating the grains separately up to their sintering temperature. The grains were heated separately until sintering temperature (Fig. 3). At this temperature the grains are already melted. These melted grains were kept at sintering temperature for $10 \mathrm{sec}$ to obtain uniform temperature in the grains. The grains were then

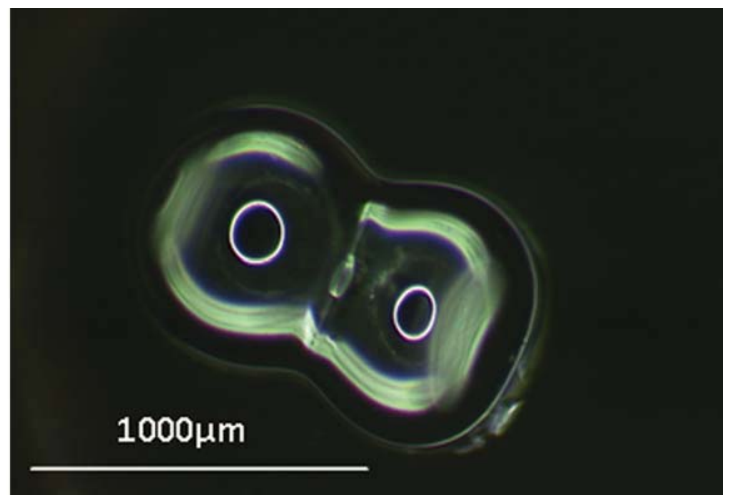

Figure 3 Coalescence of already melted grains; (a) melted grains are not yet in contact, (b) coalescence of two grains in contact. [Color figure can be viewed in the online issue, which is available at wileyonlinelibrary.com.] 

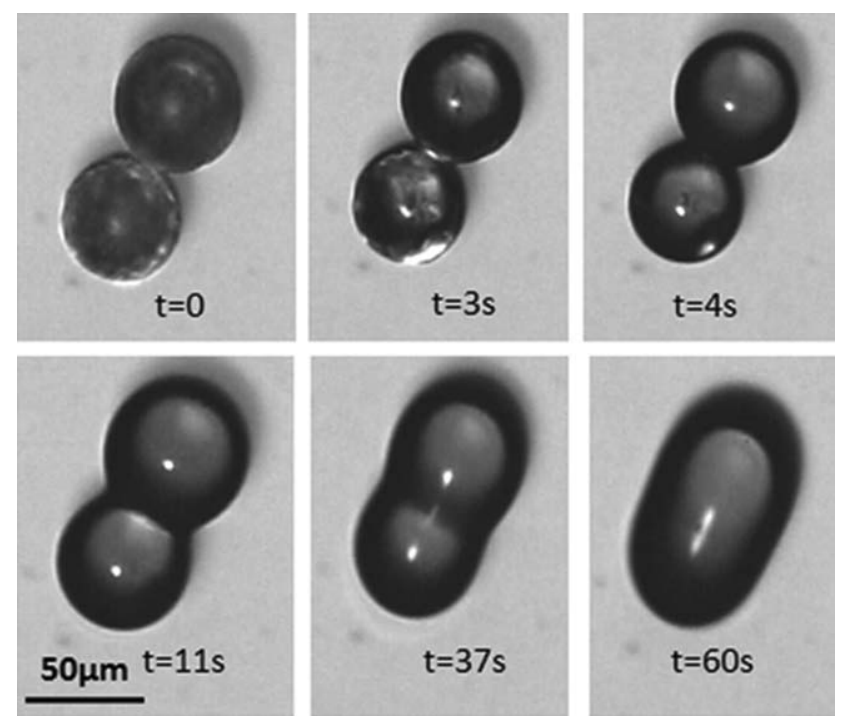

Figure 4 Different stages of PVDF particles coalescence.

brought in contact and their sintering rate was measured. This sintering rate was compared with that obtained from the previous experiment procedure.

\section{BELLEHUMEUR'S MODEL}

Bellehumeur's model as Frenkel's first model is based on the balance of the work of surface tension and the viscous dissipation.

In this model, Bellehumeur et al. calculated the work of surface tension as:

$$
W_{s}=-\Gamma \frac{d S}{d t}
$$

Where, $S$ is the total surface of the grains and $\Gamma$ is the surface tension coefficient. In this model, it is considered that the work of surface tension depends on the rate of surface reduction rather than on the surface curvature. The change of surface tension with respect to time, during the sintering process is given by:

$$
\frac{d S}{d t}=\frac{d S}{d \theta} \frac{d \theta}{d t}=-\frac{8 \pi a_{0}^{2} 2^{1 / 3} \cos (\theta) \sin (\theta)}{(1+\cos (\theta))^{4 / 3}(2-\cos (\theta))^{5 / 3}} \theta^{\prime}
$$

By replacing eq. (2) in eq. (1), they obtained:

$$
W_{s}=\Gamma \frac{8 \pi a_{0}^{2} 2^{1 / 3} \cos (\theta) \sin (\theta)}{(1+\cos (\theta))^{4 / 3}(2-\cos (\theta))^{5 / 3}} \theta^{\prime}
$$

The work of viscous forces for purely viscous model can be expressed as:

$$
W_{v}=\iiint_{v}(\tau: D) d V
$$

As explained previously, to take into account the effect of viscoelasticity of polymers in their sintering model, Bellehumeur et al used convicted Maxwell model that can be written as ${ }^{1}$ :

$$
\lambda \overbrace{\tau}+\tau=2 \eta D
$$

where $\lambda$ is the polymer relaxation time and $\overbrace{\tau}$ represents a general form of the invariant derivative of the extra-stress tensor:

$$
\overbrace{\tau}=\frac{D \tau}{D t}-\omega . \tau+\tau . \omega-a(D . \tau+\tau . D)
$$

Where $D \tau / D t$ is the substantial derivative of the extra-stress tensor and $\omega$ is the rotational tensor. ${ }^{27}$ The flow field in the sintering system is defined to be extensional and the rotational tensor in eq. (6) is equal to zero. As the rate of sintering in the processes in rotational molding is very slow ${ }^{22}$ the quasi-steady state flow is assumed as a first approximation:

$$
\tau+\lambda a(D \cdot \tau+\tau D)=2 \eta D
$$

The principal components of the extra-stress tensor are defined as:

$$
\begin{gathered}
\tau_{\mathrm{yy}}=\frac{-4 \eta \dot{\varepsilon}}{1-4 a \lambda \dot{\varepsilon}} \\
\tau_{\mathrm{xx}}=\tau_{\mathrm{zz}}=\frac{2 \eta \dot{\varepsilon}}{1+2 a \lambda \dot{\varepsilon}}
\end{gathered}
$$

By replacing these components in the eq. (4), the energy dissipated in the sintering system is calculated as:

$$
W_{v}=\iiint_{v} \tau: D d V=\frac{32 \pi a_{0}^{3} \eta \dot{\varepsilon}^{2}}{(1-4 a \lambda \dot{\varepsilon})(1+2 a \lambda \dot{\varepsilon})}
$$

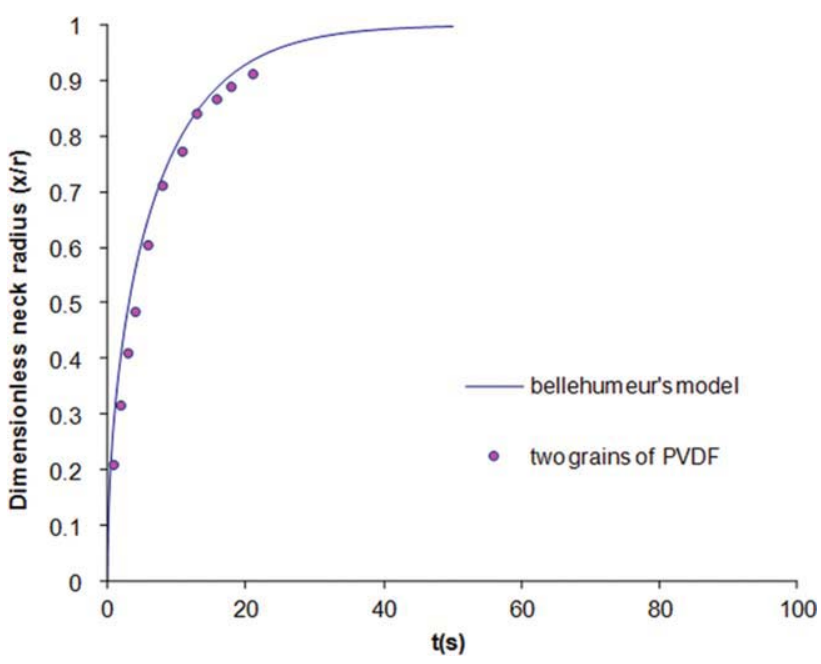

Figure 5 Comparison of the experimental results of coalescence rate of PVDF with Bellehumeur's model at $220^{\circ} \mathrm{C}$ (diameter of grains, $d=1002 \mathrm{~m}$ ). [Color figure can be viewed in the online issue, which is available at wileyonlinelibrary.com.] 


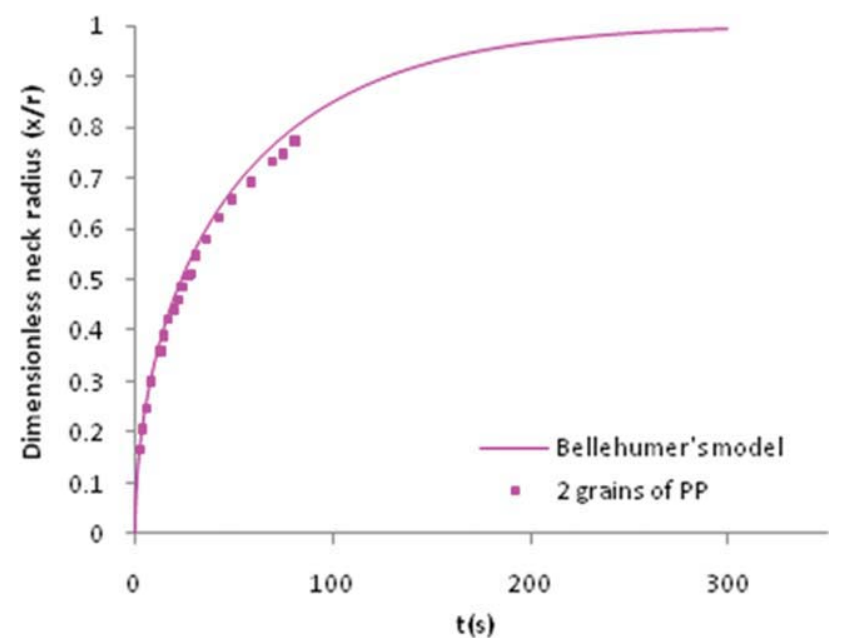

Figure 6 Comparison of the experimental results of coalescence rate of PP with Bellehumeur's model at $190^{\circ} \mathrm{C}$ (diameter of grains, $d=5002 \mathrm{~m}$ ). [Color figure can be viewed in the online issue, which is available at wileyonlinelibrary.com.]

By equating the energy dissipated in sintering system as described by eq. (10), with the calculated work of surface tension [eq. (3)], a non-linear differential equation is obtained to evaluate the sintering of two grains:
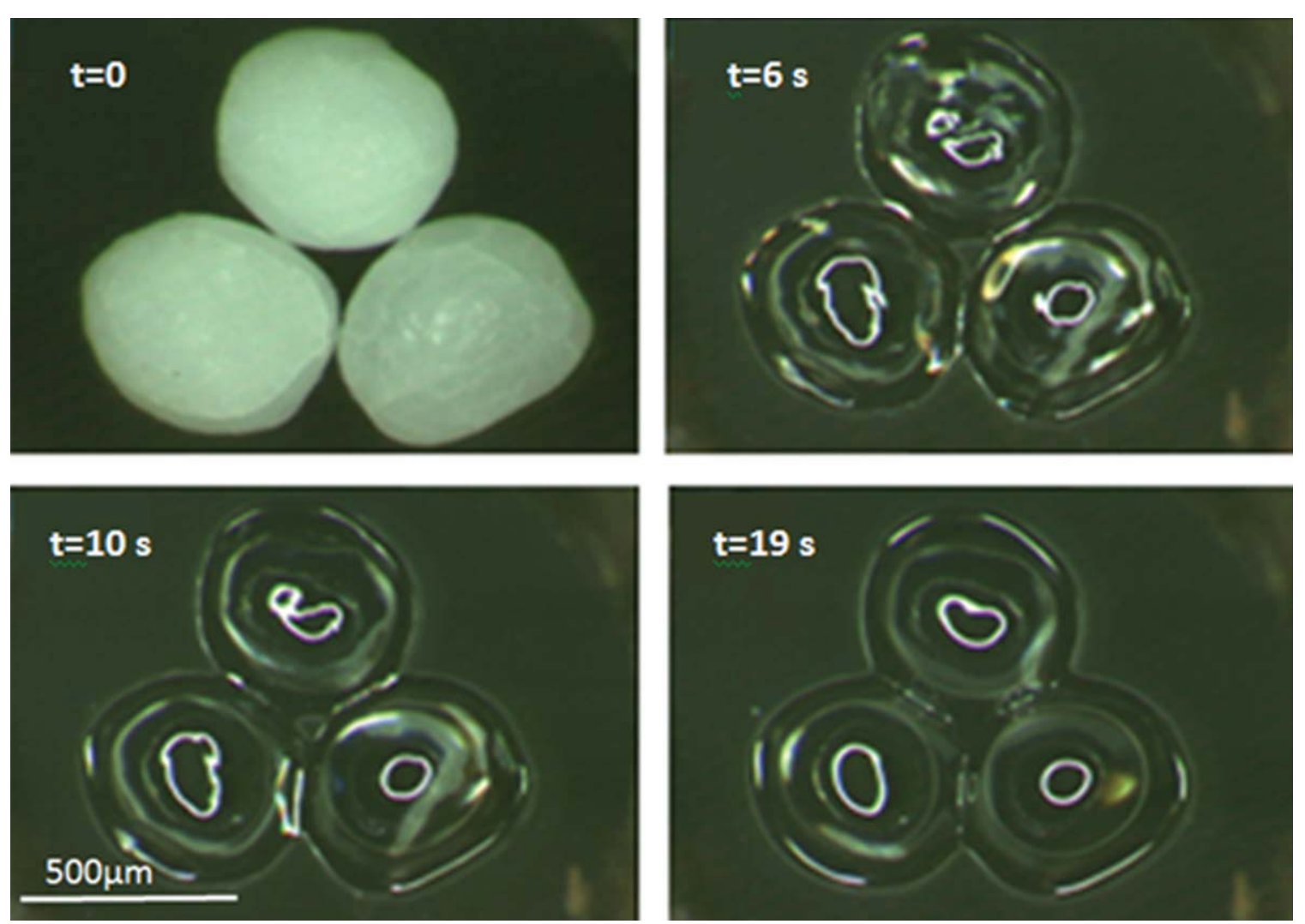

Figure 7 Simultaneous coalescence of three grains of PP at $190^{\circ} \mathrm{C}$ (diameter of grains, $d=5002 \mathrm{~m}$ ). [Color figure can be viewed in the online issue, which is available at wileyonlinelibrary.com.]

$$
8\left(a \lambda k_{1} \theta^{\prime}\right)^{2}+\left(2 a \lambda k_{1}+\frac{\eta a_{0}}{\Gamma} \frac{k_{1}^{2}}{k_{2}}\right) \theta^{\prime}-1=0
$$

where

$$
\begin{gathered}
k_{1}=\frac{\sin (\theta)}{(1+\cos (\theta))(2-\cos (\theta))} \\
k_{2}=\frac{2^{-5 / 3} \cos (\theta) \sin (\theta)}{(1+\cos (\theta))^{4 / 3}(2-\cos (\theta))^{5 / 3}}
\end{gathered}
$$

The solution of eq. (18) can be calculated numerically and sintering rate is given by:

$$
\frac{x}{a}=\sin (\theta)
$$

\section{RESULTS AND COMPARISON WITH MODEL PREDICTIONS}

Sintering experiments were performed under different conditions, and the results were compared with Bellehumeur's model. Figure 4 shows different stages of coalescence of two PDVF grains.

To verify the theoretical model and to validate our experimental setup, in the first stage, coalescence of two grains were studied. As temperature gradient 


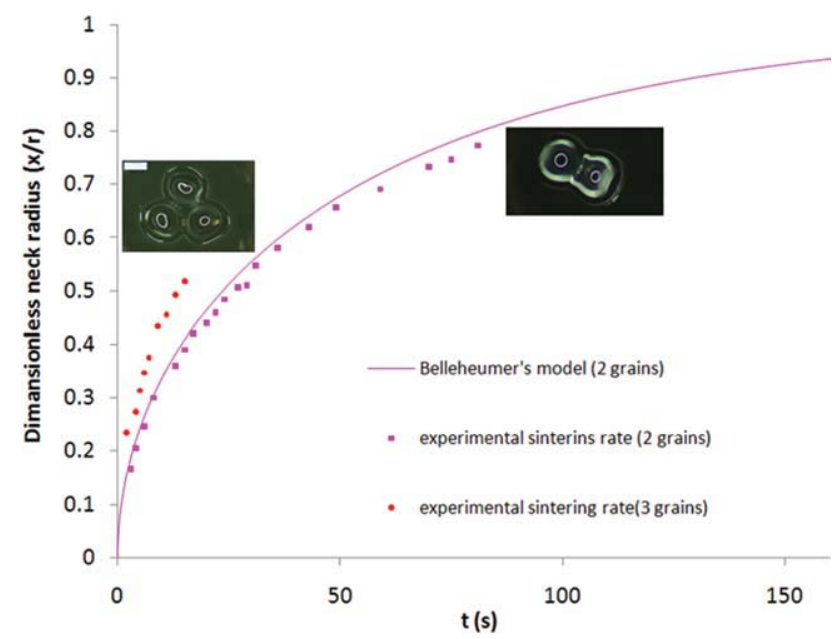

Figure 8 Comparison of sintering rate of two and three grains at $190^{\circ} \mathrm{C}(d=5002 \mathrm{~m})$. [Color figure can be viewed in the online issue, which is available at wileyonlinelibrary.com.]

inside a grain particle plays an important role in coalescence phenomenon, pre-melted PP grains were used. No preheating was performed for PVDF grains as their grain sizes are very small.

As it is shown in Figure 5, the experimental results for this polymer confirm well with those predicted by the model.

In the case of $\mathrm{PP}$, the comparison between the experimental coalescence rate of grains, with that obtained from the theoretical model (Fig. 6), shows also that this later may accurately predicts the coalescence rate of this polymer.

After the validation of theoretical model with the experimental results, in the second stage, sintering of multi-grains was studied, starting with interaction of three grains (Fig. 7). Coalescence rate of three grains was compared with that of two grains having
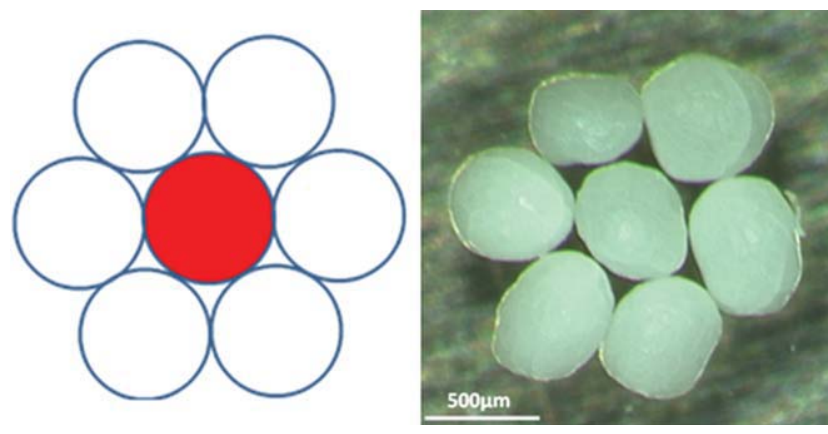

Figure 9 Maximum number of the neighbor particles of a grain. [Color figure can be viewed in the online issue, which is available at wileyonlinelibrary.com.]

the same size and heated under the same experimental conditions (Fig. 8). It can be seen that the coalescence rate of three grains is higher than that of two grains proving that the neighboring grains have an effect on coalescence rate.

As one can see in Figure 8, Bellehumeur's model is limited to two grains and can not predict the coalescence rate of three grains. So to adapt the model to coalescence of multi-grains, one should take into account the neighboring grains effect. To clarify this effect on the coalescence rate, two factors should be studied:

- Neighboring grains number.

- Neighboring grains position.

To investigate the effect of the positions of the neighboring grains, the experiment was repeated with different neighboring grain positions with respect to each other. In two dimensions, the maximum number of the neighboring particles of a grain is limited (Fig. 9). This number depends on the diameter of grains.

In the case of three grains, the position of two neighboring grains is measured by the angle formed
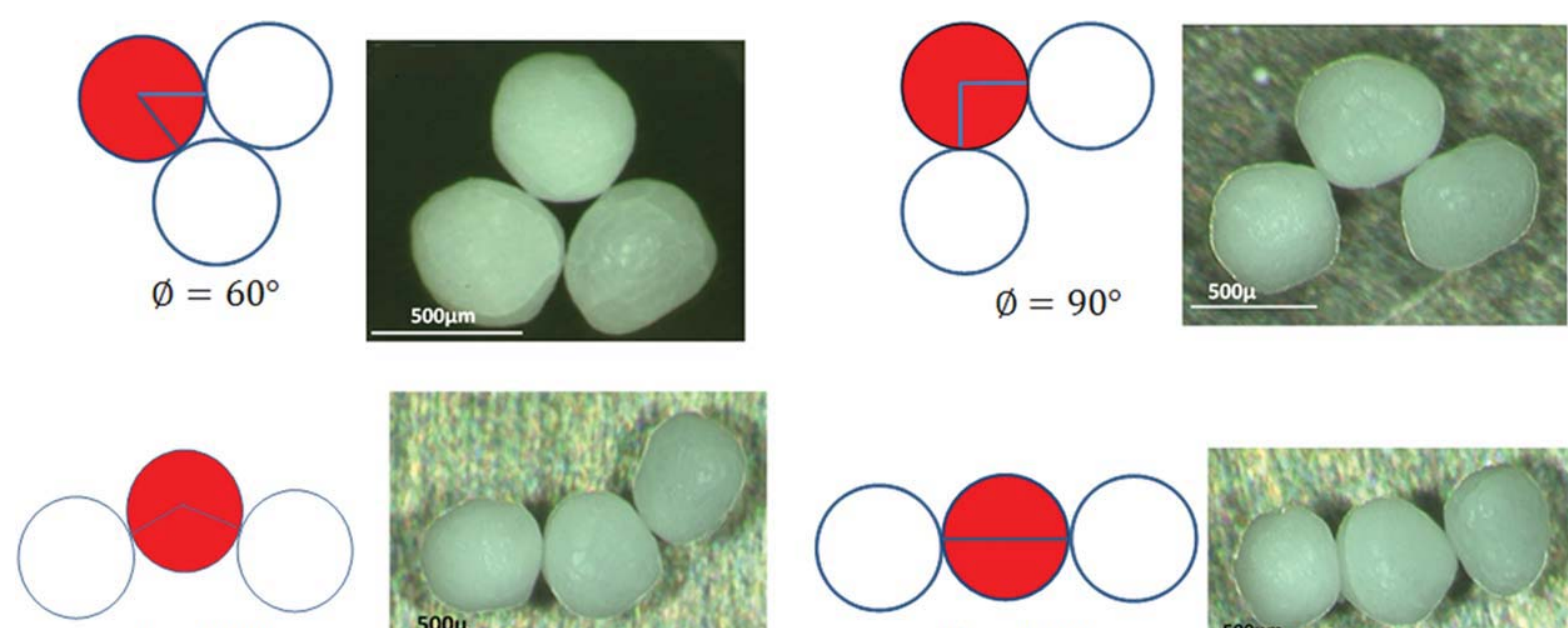

$\emptyset=120^{\circ}$
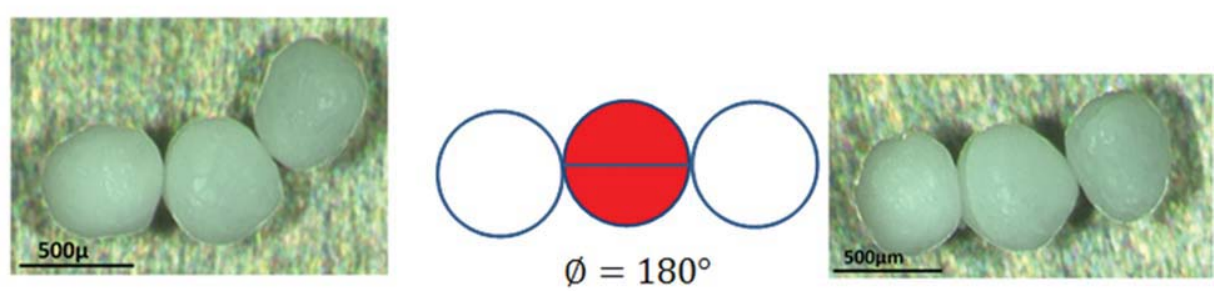

Figure 10 Four different positions of three grains in contact. [Color figure can be viewed in the online issue, which is available at wileyonlinelibrary.com.] 


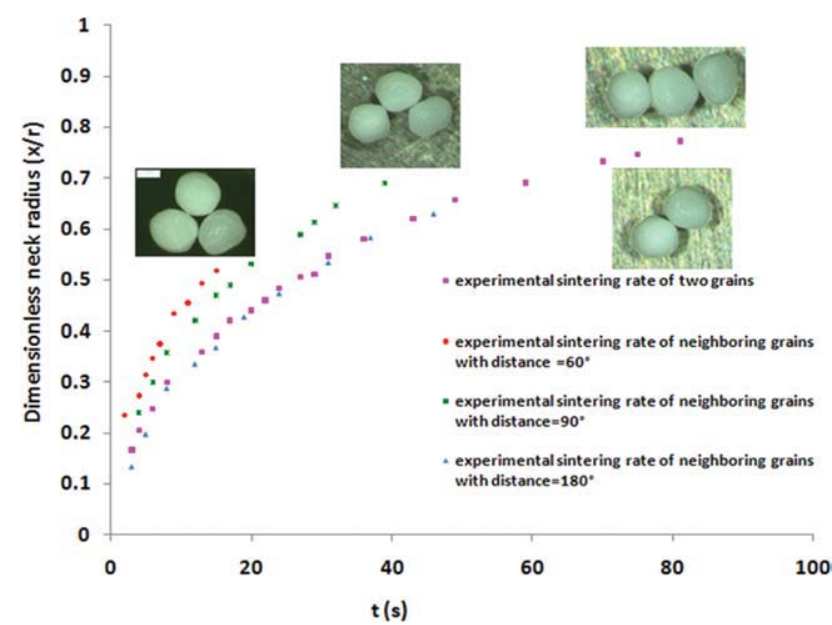

Figure 11 Comparison of the rate of coalescence of, two grains and three grains with three different positions $\left(\Phi=60^{\circ}, 90^{\circ}\right.$, and $\left.180^{\circ}\right)$ at $190^{\circ} \mathrm{C}(d=5002 \mathrm{~m})$. [Color figure can be viewed in the online issue, which is available at wileyonlinelibrary.com.]

between their centers with respect to the centre of the third grain. Four different positions (60, 90, 120, and 180) were considered that are shown in Figure 10. The coalescence rate for these four positions was measured and is shown in Figure 11.

Coalescence progress percentage after $15 \mathrm{sec}$ was compared in Table II for different grains positions (showed in Fig. 10).

Presented results in Table II show that coalescence rate increase with decreasing $\phi$. One can see also, for $\phi=180^{\circ}$ (the distance between neighboring grains is maximum) coalescence rate is almost equal to the coalescence rate of two grains. In the other hand, at $\phi=180^{\circ}$, the effect of neighboring grain on the coalescence rate is negligible.

\section{MODEL MODIFICATION}

The results obtained from three grains in different positions were compared with the sintering rate of two grains. It was observed that as the distance between the grains reduced (that means $\Phi$ decreased) the rate of coalescence increased. Taking the ratio of each of these coalescence rates with the coalescence rate of two grains yields an exponential curve shown in Figure 12. Based on this observation

TABLE II

Coalescence Progress of Three Grains with Different Positions (Fig. 10) and Comparison with Coalescence Progress of Two Grains at $t=15 \mathrm{~s}$ (Results Obtained from Fig. 11)

\begin{tabular}{lcccc}
\hline \multicolumn{1}{c}{ Number of grains } & 3 & 3 & 3 & 2 \\
\hline$t(\mathrm{~s})$ & 15 & 15 & 15 & 15 \\
$\phi^{\circ}$ & 60 & 90 & 180 & - \\
Coalescence progress $\%$ & 52 & 47 & 39 & 38 \\
\hline
\end{tabular}

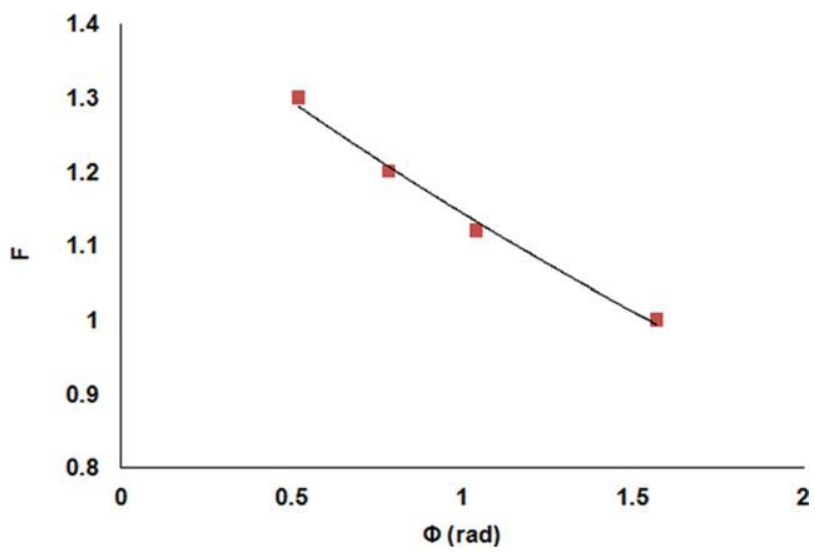

Figure 12 Sintering rate change's coefficient with presence of neighboring grains as a function of the angle between the contacts. [Color figure can be viewed in the online issue, which is available at wileyonlinelibrary.com.]

we propose a geometric parameter $(F)$ to compensate the sintering rate of three grains architecture for different positions.

The work done by surface tension, given by eq. (3), was valid for two grains but it does not accurately model the phenomenon for the case of multigrains. In the case of two grains, grains surface change is the only parameter that affects the work of surface tension [eq. (1)]. Results obtained during this work show that in the case of multi-grains, the work done by surface tension changes with the position of the neighboring grains (system's geometry). To compensate the effect of a neighbouring grain, it is judicious to incorporate a geometrical parameter $F$ which is a function of the contact angle $\phi$ between the grains. $F$ is the coefficient of work of surface tension that modifies this work in function of system's geometry. On the other hand, with introducing this coefficient in eq. (1) [resulting eq. (15)], one takes

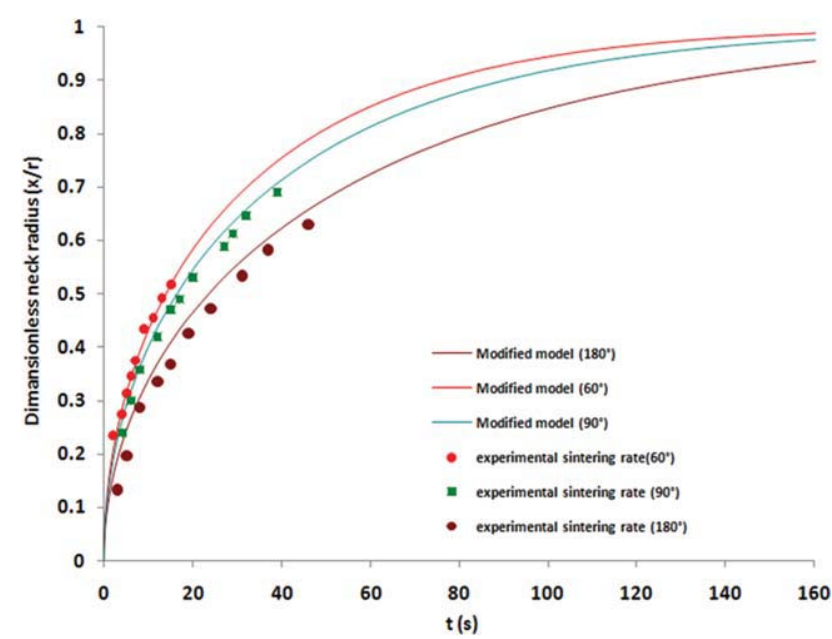

Figure 13 Comparison of the experimental results of multi-grains coalescence with the Belleheumer's modified model. [Color figure can be viewed in the online issue, which is available at wileyonlinelibrary.com.] 

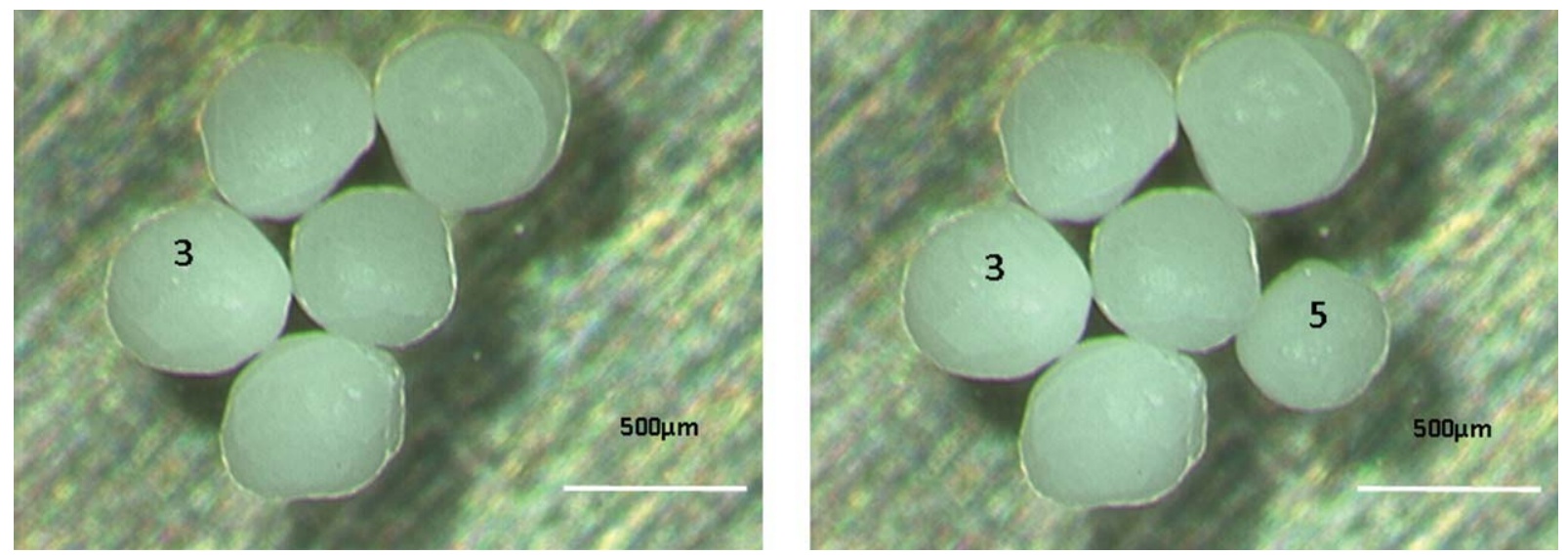

Figure 14 Neighbouring and non-neighbouring grains of grains 3. [Color figure can be viewed in the online issue, which is available at wileyonlinelibrary.com.]

into account the role of system's geometry (the position of neighboring grains) in the calculations of work of surface tension. This parameter that changes by system's geometry (distance between the grains contacts), modifies the work of surface tension according to different geometries.

$$
W_{s}=-F(\phi) \Gamma \frac{d S}{d t}
$$

In the case of three grains, $F$ was calculated for different grain positions, shown in Figure 12. Based on these results, we identified $F$ as:

$$
F=\frac{1}{2}+\exp (\phi / 2)
$$

where $F$ is the coefficient of curvature, $\phi$ is the angle between two contacts (Fig. 12). Introducing this coefficient into the eq. (3) yields:

$W_{s}=\Gamma\left[\frac{1}{2}+\exp (\phi / 2)\right]^{2} \frac{8 \pi a_{0}^{2} 2^{1 / 3} \cos (\theta) \sin (\theta)}{(1+\cos (\theta))^{4 / 3}(2-\cos (\theta))^{5 / 3}} \theta^{\prime}$

By equating the energy dissipated in sintering system as described by eq. (10), with the calculated work of surface tension for multi-grains [eq. (17)], a non-linear differential equation is obtained to evaluate the sintering of neighboring grains positioned at different angles:

$$
\left.8\left(a \lambda k_{1} \theta^{\prime}\right)^{2}+2 a \lambda k_{1}+\frac{\eta a_{0}}{\Gamma\left(\frac{1}{2}+\exp (\phi / 2)\right)^{2}} \frac{k_{1}^{2}}{k_{2}}\right) \theta^{\prime}-1=0
$$

where

$$
k_{1}=\frac{\sin (\theta)}{(1+\cos (\theta))(2-\cos (\theta))}
$$

$$
k_{2}=\frac{2^{-5 / 3} \cos (\theta) \sin (\theta)}{(1+\cos (\theta))^{4 / 3}(2-\cos (\theta))^{5 / 3}}
$$

Obtained model was verified by experiment results. Figure 13 shows the coalescence rate of three grains, calculated experimentally and numerically for three different positions. It can be seen that the proposed model coincides well with the experimental results.

In order to investigate the effect of non-neighboring grains, the coalescence experiment was repeated with 5 grains and 6 grains. The position of these grains is shown in Figure 14, where grain number 5 is the non-neighboring grain for grain number 3 . The coalescence rate of grain number 3 (with its neighbor at right) for both of experiments is shown in Figure 15. It can be seen clearly that there is not a

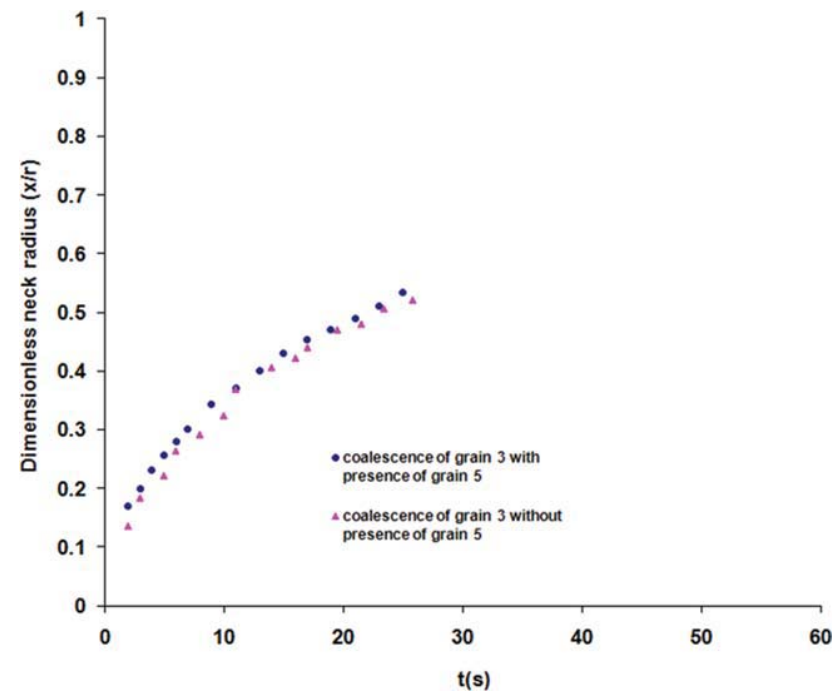

Figure 15 The effect of presence of non-neighboring grain on the sintering rate at $190^{\circ} \mathrm{C}(d=4502 \mathrm{~m})$. [Color figure can be viewed in the online issue, which is available at wileyonlinelibrary.com.] 
considerable difference between the sintering rates of the grain, proving that the non-neighboring grain has a negligible effect on the coalescence rate of a grain.

\section{CONCLUSIONS}

Sintering is very sensible to operating conditions. Small temperature changes or gradients during sintering can change its rate. A comparison of experimental data with the sintering model suggested by Bellehumeur was made. This model calculates the rate of coalescence of particles with balance the work of surface tension and dissipation work. Obtained results show that it can predict successfully the rate of coalescence of two grains. But in the case of coalescence of multi-grains, there is a considerable difference between grains coalescence rate and model's prediction.

Surface tension is the driving force of purely viscous sintering and viscoelastic sintering. Bellehumeur considered that this force depends only on the surface reduction. But obtained experimental results during this work show that, it depends not only on the variation of surface of grains but also the presence and position of neighboring grains. Presence of neighboring grains affects the curvature of coalescing system and changes the sintering rate. The amount of this effect depends on the distance between the contacts. Decreasing the distance between the contacts, increases their effects in the sintering rate of the other. As in rotational molding condition, one particle is in contact with several other particles, it is important to take into account this factor in the sintering rate calculus.

The effect of non-neighboring grains also studied during this work. It is important to determine the effect of non-neighboring grains, because in the mass of grains, on grains can have limited number of neighboring grains, but also several non neighboring ones. Obtained results showed that the effect of non-neighboring grains in the sintering rate is negligible.

We modified Bellehumeur's model by taking into account the effect of neighboring grains and their positions. Comparison of numerical results obtained by modified model and experimental results obtained during this work show a good accord between them. This modified model can be helpful to study the densification of powders, where sintering of several grains happens simultaneously.

\section{References}

1. Frenkel, J. J Phys 1945, 9, 385.

2. Thummler, F.; Thomma, W. Met Rev 1967, 12, 69.

3. Mazur, S. In Polymer Powder Technology; Narkis, M.; Rosenzweig, V., Eds.; Wiley: Chichester, 1995; p 157.

4. Takacs, E.; Bellehumeur, C.; Vlachopoulos, J.; Bisaria, M. K. Rotation 1994, 3, 12.

5. Kingery, W.; Berg, M. J Appl Phys 1955, 26, 1205.

6. Kuczynski, G. Metall Trans AIME 1949, 185, 169.

7. Rosenzweig, N.; Narkis, M. Polym Eng Sci 1981, 21, 582.

8. Kuczynski, G.; Neuville, C. B.; Toner, H. P. J Appl Polym Sci 1970, 14, 2069.

9. Pokluda, O. B.; Bellehumeur, C.; Vlachopoulos, J. AIChE J 1997, 43, 3253.

10. Eshelby, J. D. Discussion. In: Seminar on the kinetics of sintering, 1949: Shaler A. J., 1949, 806.

11. Jagota, A.; Dawson, P. J Am Ceram Soc 1990, 73, 173.

12. Vande Vorst, G. Ph.D. Dissertation, Eindhoven University of Technology, The Netherlands, 1994.

13. Wakai, F.; Yoshida, M.; Shinoda, Y.; Akatsu, T. Acta Mater 2005, 53, 1361.

14. German, R. Powder Metallurgy Science, 2nd ed., Metal Powder Industries Federation Series; Metal Powder Industries Federation: Princeton, NJ, 1994; 242 p.

15. Ashby, M. Acta Metal 1974, 22, 275.

16. Kingery, M.; Bowen, H.; Uhlmann, D. Introduction to Ceramics; John Wiley and Sons, Wiley, New York, 1976.

17. Bellehumeur, C. T. Ph.D. Dissertation, McMaster University, 1997.

18. Lu, P.; German, R. M. J Mater Sci 2001, 36, 3385.

19. Plazek, D.; Mazur, S. Prog Org Coat 1994, 24, 225.

20. Lontz, J. F. Sintering of Polymer Materials, Fundamental Phenomena in the Materials Sciences; Plenum Press: New York, 1964; Vol. 1, p 25.

21. Narkis, M. Polym Eng Science 1979, 19, 889.

22. Bellehumeur, C.; Kontopoulou, M.; Vlachopoulos, J. Rheol Acta 1998, 37, 270.

23. Pérot, E. Ph.D. Dissertation, L'institut national des sciences appliquées de Lyon, 2006.

24. Brostow, W.; Cassidy, P. E.; Macossay, J.; Pietkiewicz, D.; Venumbaka, S. Polym Int 2003, 52, 1498.

25. Kopczynska, A.; Ehrenstein, G. W. J Mater Ed 2007, $29,325$.

26. Bismarck, A.; Kumru, M. E.; Springer, J. J Colloid Interface Sci 1999, 217, 377.

27. Joseph, D. Fluid Dynamics of Viscoelastic Liquids; Springer: New York, 1990. 